\title{
DISCURSO DE RECEPÇÃO DO TÍTULO DE PROFESSOR EMÉRITO
}

SPEECH OF INVESTITURE AS AN EMERITUS PROFESSOR

Fábio Konder Comparato

Sejam minhas primeiras palavras destinadas a reverenciar a memória do Professor Goffredo da Silva Telles Jr, que nos deixou recentemente. Ele marcou gerações de estudantes, inclusive a minha, com o selo da bondade. Legou a todos nós, entre outras preciosas lições, a de que o Amor está sempre acima da Justiça.

Ao receber o honroso título que a Congregação generosamente me outorgou, devo reconhecer com humildade que, nas quatro décadas por mim dedicadas à docência nesta Faculdade, mais aprendi do que ensinei.

Parece-me, portanto, justo expor agora, nesta sessão cuja solenidade não elimina o seu caráter afetivo, um pouco do que me foi dado aprender sobre a vida jurídica e a função do ensino superior neste País.

No conto $O$ Espelho, de Machado de Assis, o narrador assevera a seus ouvintes espantados que cada um de nós possui duas almas. Uma exterior, que exibimos aos outros, e com qual nos julgamos a nós mesmos de fora para dentro. Outra interior, raramente exposta aos olhares externos, com a qual julgamos o mundo e a nós mesmos, de dentro para fora.

Penso que algo de semelhante ocorre em matéria de ordenações jurídicas nacionais. Em cada país, há um direito oficial publicado, isto é, exposto ao público, e há também um direito não oficial, encoberto aos olhares externos, e que regula os fatos atinentes à vida por assim dizer íntima da nação.

Não é difícil perceber o caráter essencialmente dúplice do direito brasileiro, nos dois sentidos da palavra: dobrado e dissimulado.

As Constituições aqui promulgadas apresentam-se, invariavelmente, sob a aparência de indumentárias de gala, exibidas com orgulho aos estrangeiros como prova de nosso caráter civilizado. São vestes litúrgicas, envergadas por doutores e magistrados nas cerimônias do culto oficial. Para o dia-a-dia doméstico, contudo, preferimos, como é natural, usar trajes menos vistosos e de feitio mais adaptado às linhas do nosso corpo.

A duplicidade do direito brasileiro transparece também quando o acompanhamos em sua evolução histórica. Na sucessão dos diferentes regimes políticos por nós adotados, temos assistido ao amálgama do novo com o velho, do direito revogado com o direito revogador. $\mathrm{O}$ antigo protagonista, embora retirado do proscênio, não desaparece do teatro jurídico: é simplesmente relegado aos bastidores, para ressurgir em cena no momento oportuno.

Separamo-nos de Portugal, mas fizemos do Príncipe herdeiro português nosso primeiro imperador, o qual voltou à terra natal poucos anos após para retomar a coroa do velho reino. 
Do modelo republicano, só adotamos, em 1889, os aspectos exteriores: a abolição da monarquia e dos privilégios nobiliárquicos. Mantivemos em pleno vigor o velho costume denunciado por Frei Vicente do Salvador, já no início do século XVII: "Nem um homem nesta terra é repúblico, nem zela e trata do bem comum, senão cada um do bem particular".

A Revolução de 1930, desencadeada com o objetivo declarado de pôr cobro às fraudes eleitorais, desembocou alguns anos após em um regime sem eleições, uma ditadura que manteve o velho coronelismo no campo e contou com o apoio das novas massas de trabalhadores nos centros urbanos.

Ao término de dois regimes autocráticos - o Estado Novo getulista e o regime militar instaurado com o golpe de 1964 - promulgamos uma lei de anistia para os crimes políticos. Por trás desse direito oficial, no entanto, havia o direito não declarado, mas subentendido, segundo o qual anistiados também estavam os agentes públicos e seus cúmplices na sociedade civil, responsáveis pelo cometimento de várias atrocidades contra opositores ao regime.

Creio não haver melhor simbologia para o caráter dual do nosso ordenamento jurídico, do que a figura de Janus bifronte, o deus romano da passagem. Quando o direito oficial não se opõe aos poderosos, ele é tido e proclamado como o único legítimo e em vigor. Basta, no entanto, surgir um mínimo conflito entre os interesses particulares dos que mandam e as normas contidas na Constituição e nas leis, para que se abram automaticamente as portas de comunicação com o outro ordenamento não declarado, que consagra o status dominii tradicional.

Foi por essa razão, aliás, que o sistema capitalista fixou, tão rapidamente, fundas raízes entre nós. Graças à sua natureza camaleônica, ele logra sempre revestir de cores claras a mais sombria realidade. Sob o rebuço da autoridade pública, os agentes estatais não hesitam em atuar no interesse privado. A resplandecência de Mercado, deus da liberdade empresarial, ofusca nossa visão, impedindo-nos de ver com nitidez o sacrifício quotidiano, em seu altar, da liberdade de trabalhadores e consumidores. De acordo com informe oficial das Nações Unidas, somos o segundo país de maior desigualdade social no mundo. Pouco nos importa, contudo, essa trágica realidade, pois o princípio da isonomia abre, solenemente, nossa declaração constitucional de direitos fundamentais.

Dois exemplos históricos ilustram à perfeição a duplicidade por assim dizer orgânica de nosso sistema jurídico: a escravidão negra e a adoção do regime democrático.

A Constituição de 1824 declarou textualmente "desde já abolidos os açoites, a tortura, a marca de ferro quente e todas as demais penas cruéis" (art. 179, XIX).

Em 1830, porém, o Código Criminal previu, em seu art. 44, a pena de galés, que sujeitava os réus "a andarem com calceta no pé e corrente de ferro, juntos ou separados, 
e a empregarem-se nos trabalhos públicos da província, onde tiver sido cometido o delito, à disposição do Governo". Escusa dizer, embora o Código não o declarasse, que essa penalidade patentemente cruel só se aplicava aos escravos.

E havia mais. Apesar da expressa proibição constitucional, os cativos foram, até a lei de 1886, ou seja, até as vésperas da abolição, marcados com ferro em brasa, e regularmente sujeitos à pena de açoite. O mesmo Código Criminal de 1830, em seu art. 60, fixava para os escravos o máximo de 50 (cinqüenta) açoites por dia. Mas a disposição legal nunca foi respeitada. Era comum o infeliz sofrer até duzentas ou trezentas chibatadas diárias e morrer em conseqüência; como sucedeu com dois escravos condenados pelo tribunal do júri de Paraíba do Sul, em 1886, o que levou à rápida aprovação da lei a que acabo de me referir. Tudo isso, para não falar dos castigos mutilantes sistematicamente aplicados aos cativos, como todos os dentes quebrados, dedos decepados ou seios furados.

Na realidade, embora mantido em segundo plano, o direito não oficial da escravidão jamais deixou de existir. Um bom exemplo, a esse respeito, foi a permanência do tráfico negreiro por longos anos, em situação de gritante ilegalidade.

Em 1831, após dois tratados celebrados com a Inglaterra e não cumpridos, os quais equipararam o comércio infame à pirataria, a Regência promulgou a Lei de 7 de novembro, declarando livres de pleno direito todos os africanos desembarcados no Brasil após a sua entrada em vigor.

Até a promulgação da Lei Euzébio de Queiroz, em 1850, contudo, esse aparato jurídico oficial só existiu literalmente "para inglês ver". Como assinalou o grande rábula negro Luiz Gama - cuja entrada nesta Faculdade foi impedida pelo racismo de alguns estudantes, mas que acabou por partilhar o escritório de advocacia de dois de nossos antigos catedráticos, os Doutores Januário Pinto Ferraz e Dino Bueno - na prática tudo transcorria como se o tráfico fosse perfeitamente legal:

Os carregamentos eram desembarcados publicamente, em pontos escolhidos das costas do Brasil, diante das fortalezas, à vista da polícia, sem recato nem mistério. Eram os africanos, sem embaraço algum, levados pelas estradas, vendidos nas povoações, nas fazendas, e batizados como escravos pelos reverendos, pelos escrupulosos párocos!... ${ }^{1}$

Se considerarmos agora a questão do entendimento dado entre nós à idéia de democracia, encontraremos idêntica anfibologia, a mesma exibição de vistosa fachada para ocultar o interior sórdido do prédio.

$\overline{1}$ Citado por MENUCCI, Sud. O precursor do Abolicionismo no Brasil (Luiz Gama). São Paulo: Companhia Editora Nacional, coleção Brasiliana, vol. 119, p. 171. 
Em maio de 1811, nas páginas do Correio Braziliense, editado em Londres, Hipólito José da Costa fez questão de lançar severa advertência contra a adoção entre nós do regime de soberania popular:

\begin{abstract}
Ninguém deseja mais do que nós as reformas úteis; mas ninguém aborrece mais do que nós, que essas reformas sejam feitas pelo povo; pois conhecemos as más conseqüências desse modo de reformar; desejamos as reformas, mas feitas pelo governo; e urgimos que o governo as deve fazer enquanto é tempo, para que se evite serem feitas pelo povo. ${ }^{2}$
\end{abstract}

Na Fala do Trono dirigida aos constituintes de 1823, nosso primeiro imperador declarou esperar que a Constituição a ser elaborada pusesse "barreiras inacessíveis ao despotismo, quer real, quer democrático". 3

Foi somente a partir do término da Guerra do Paraguai, que a idéia de democracia, expurgada de suas conotações subversivas, começou a ser favoravelmente invocada. No Manifesto Republicano de 1870, o vocábulo e várias expressões cognatas solidariedade democrática, liberdade democrática, princípios democráticos ou garantias democráticas - aparecem nada menos do que 28 vezes. Um dos seus tópicos é intitulado a verdade democrática. Mas nem uma palavra é dita sobre a escravidão. É sabido, aliás, que os líderes do partido republicano opuseram-se à Lei do Ventre Livre, e só aceitaram a emancipação dos cativos em 1887, ou seja, quando ela já era um fato quase consumado.

Ao final da década de 70, iniciou-se o movimento pela reforma do sistema eleitoral, com a abolição das eleições indiretas. O gabinete Sinimbu tentou aprovar uma emenda constitucional nesse sentido e, para tranquilizar a classe dominante dos grandes proprietários rurais, propôs a eliminação do voto dos analfabetos e a elevação do censo, isto é, da renda mínima anual exigida para a inscrição nas listas eleitorais.

Foi então que se levantou o Deputado José Bonifácio, o Moço, Professor ilustre desta Faculdade e, seguramente, o maior tribuno parlamentar que este país jamais conheceu. Quando subiu à tribuna da Câmara, na tarde do dia 28 de abril de 1879, a Casa estava à cunha e a sessão teve que ser interrompida várias vezes, diante das pressões do público, que pretendia ingressar no recinto e era barrado pelo serviço de ordem.

\footnotetext{
"Os sustentadores do projeto", disse ele sob intenso aplauso, "depois de meio século de governo constitucional, repudiam os que nos mandaram a esta câmara, aqueles que são os verdadeiros criadores da representação nacional. Por quê? Porque não sabem ler, porque são analfabetos! Realmente
}

\footnotetext{
2 Cf. LIMA SOBRINHO, Barbosa. Antologia do Correio Braziliense. Rio de Janeiro: Editora Cátedra - MEC, 1977. p. 79-80.

3 Id. Ibid., p. 16.
} 
a descoberta é de pasmar! Esta soberania de gramáticos é um erro de sintaxe política (prorrompem aplausos e risos no plenário). Quem é o sujeito da oração? (Hilaridade prolongada). Não é o povo? Quem é o verbo? Quem é o paciente? Ah! Descobriram uma nova regra: é não empregar o sujeito. Dividem o povo, fazem-se eleger por uma pequena minoria, e depois bradam com entusiasmo: Eis aqui a representação nacional!"

Diante do malogro do Gabinete Sinimbu em conseguir ver aprovada a mudança constitucional, o Imperador designou como Primeiro-Ministro o Conselheiro José Antonio Saraiva, dito o Messias de Ipojuca. Este não teve dúvidas: concentrou seus esforços retóricos na demonstração de que o regime do povo soberano, até então tido como fator de convulsão social, já se havia aclimatado a estes trópicos. Em sessão da Assembléia, na legislatura de 1880, declarou:

Gozamos de plena democracia no Brasil. [...] Convivemos com qualquer pessoa; pomos os libertos à nossa mesa e confiamos mais nos libertos dignos de confiança do que em muitos cidadãos brasileiros. ${ }^{5}$

Faltou apenas dizer que, uma vez abolida a escravidão, criaríamos aqui uma sociedade perfeitamente igualitária. O que não demorou muito a ser oficialmente proclamado. Em Mensagem ao Congresso Legislativo de São Paulo no quadriênio 1912 - 1916, Francisco de Paula Rodrigues Alves, que havia sido Presidente da República de 1902 a 1906, pôde declarar en passant, como se se tratasse de verdade evidente por si mesma: "Entre nós, em um regimen de franca democracia e completa ausência de classes sociais..."6

Púnhamos então na sombra o fato incômodo de que à época em que foram ditas tais palavras, o eleitorado nacional não ultrapassava $1,5 \%$ da população total do país. Mas afinal, tínhamos eleições. Logo, tínhamos democracia. "Uma democracia à brasileira", como disse o General que mandou prender o grande advogado Sobral Pinto em 1968. Ao que este retrucou: "General, eu só conheço peru à brasileira".

Efetivamente, ao procurarem justificar o golpe de Estado de 1964, os chefes militares não hesitaram, no chamado ato institucional $n^{\circ} 1$, de 9 de abril de 1964 , em se declararem representantes do povo brasileiro, para exercer em seu nome o poder

4 Apud HOLANDA, Sérgio Buarque de. História geral da civilização brasileira. São Paulo: Difusão Européia do Livro, 1972. t. II, v. 5, p. 206.

5 Apud GRAHAM, Richard. op. cit., p. 32. Observe-se que os libertos da escravidão não gozavam de plena cidadania.

6 Cf. EGAS, Eugenio (Org.). Galeria dos presidentes de São Paulo: período republicano 1889 - 1920. São Paulo: Publicação Official do Estado de São Paulo, 1927. 
constituinte. Seis meses depois, no ato institucional $\mathrm{n}^{\circ}$ 2, o Marechal Castello Branco e seus ministros fizeram questão de dizer que a "ordem revolucionária [...] procura colocar o povo na prática e na disciplina do exercício democrático".

A invocação retórica da democracia para encobrir todos os crimes do regime autoritário atingiu seu ponto culminante com o infame ato institucional $\mathrm{n}^{\mathrm{o}} 5$, de 13 de dezembro de 1968, redigido por ninguém menos que um Professor Catedrático e exDiretor desta Casa. O formidável ucasse abriu as portas ao terrorismo de Estado, a fim de assegurar ipsis verbis "autêntica ordem democrática, baseada na liberdade, no respeito à dignidade da pessoa humana".

Se voltarmos agora os olhos para a realidade atual, é doloroso reconhecer que a democracia permanece um "lamentável mal-entendido", como assinalou Sérgio Buarque de Holanda.

A Constituição Federal de 1988 abre-se com a declaração solene de que "a República Federativa do Brasil [...] é um Estado democrático de Direito", no qual "todo poder emana do povo, que o exerce por meio de representantes eleitos ou diretamente" $\left(\operatorname{art.~} 1^{\circ}\right)$.

Acontece que essa Constituição, como todas as que a precederam, não foi aprovada pelo povo. Pior: os que se intitulavam representantes populares, ao redigirem a Constituição - tal como sucedeu invariavelmente no passado - arrogaram-se o poder exclusivo de modificá-la, sem consulta ao representado. Até a data de hoje, o texto de 1988 foi emendado (ou melhor, remendado) sessenta e três vezes; o que perfaz a apreciável média de mais de 3 emendas por ano. Nada menos do que 17 dessas mudanças textuais atingiu o Ato das Disposições Constitucionais Transitórias; evidenciando que, até hoje, a Constituição de 1988 ainda não entrou definitivamente em vigor. Ora, em nenhuma dessas ocasiões, o povo soberano foi consultado.

Na verdade, ao lograrem - sem o menor protesto de quem quer que seja - essa auto-atribuição exclusiva do poder de mudança constitucional, os parlamentares tornaramse, escusa frisá-lo, os verdadeiros titulares da soberania. Constitucionalizamos, por essa forma, um duplo regime político: o efetivo, de natureza tradicionalmente oligárquica, e o simbólico, de expressão democrática.

Uma análise ainda que superficial de outras disposições da Constituição de 1988 confirma a existência dessa duplicidade inerente ao regime político adotado e a toda a nossa tradição jurídica.

$\mathrm{O}$ art. 14 declara que a soberania popular será exercida não só pelo sufrágio eleitoral, mas também mediante plebiscitos e referendos, e ainda pela iniciativa popular - entenda-se, meramente legislativa. No art. 49, inciso XV, porém, a Constituição inclui na competência exclusiva do Congresso Nacional "autorizar referendo e convocar plebiscito". De acordo com o entendimento prevalecente, tais atos de autorização e convocação são 
condições indispensáveis para que o povo tenha o direito de manifestar sua vontade política. Ou seja, o mandante está proibido de tomar decisões, a não ser com a prévia licença do mandatário; o que representa, sem dúvida, original criação do espírito jurídico brasileiro!

Objetar-se-á, provavelmente, que essa visão severa de nossa vida pública não considera o avanço realizado quanto à proteção dos direitos humanos com a Constituição de 1988.

Indubitavelmente, seria injusto negar esse progresso ético no nível do direito escrito. Mas teria ele, porventura, eliminado nessa matéria a vigência de outro direito, não formalizado na Constituição?

Consideremos um exemplo recente. De um lado, o esbulho possessório de terras públicas na Amazônia Legal é legitimado por meio de medida provisória, depois convertida em lei. De outro lado, a ocupação pacífica de latifúndios improdutivos por agricultores sem terra, ou a instalação de famílias sem teto em grandes áreas urbanas não edificadas, é sistematicamente reprimida com violência pela Polícia e denunciada como grave perturbação da ordem pública nos meios de comunicação de massa. É que de um lado temos a propriedade pública, propriedade do povo, e de outro, a propriedade privada; sendo óbvio, mas nunca explicitado, que a última é mais importante que a primeira.

Burla análoga verificamos em matéria de liberdade de expressão. No passado, jornais e demais periódicos impressos constituíam um instrumento indispensável de contrapoder diante do arbítrio estatal. No mundo contemporâneo, porém, os meios de comunicação de massa, com raras exceções, tornaram-se objeto de oligopólio de grandes grupos empresariais, e atuam como centros de manipulação da opinião pública e de pressão sobre os órgãos do Estado, visando ao atendimento das reivindicações das classes dominantes.

É lamentável que as instituições universitárias, de modo geral, tenham permanecido indiferentes a todos esses males, como se eles não lhes dissessem respeito.

Três funções são oficialmente reconhecidas às Universidades: o ensino, a pesquisa e a prestação de serviços à comunidade.

Quanto ao ensino, constitui um escárnio verificar que as instituições universitárias, sobretudo as financiadas com recursos públicos, como a nossa, tendem a formar mais profissionais técnicos para o mundo empresarial, do que defensores dos direitos dos pobres e abandonados. Importa lembrar que as Universidades públicas do Estado de São Paulo têm seu financiamento atrelado à arrecadação do ICMS, que é um imposto indireto, cujo peso econômico recai proporcionalmente muito mais sobre os contribuintes pobres. É, portanto, da mais estrita justiça que retribuamos a eles, em educação, que deles recebemos em recursos financeiros. 
No tocante à pesquisa, o dever máximo de uma Universidade hoje, não só no Brasil, mas no mundo todo, é o de conceber soluções alternativas para o sistema capitalista oligárquico, que representa o grande flagelo social do mundo contemporâneo.

Finalmente, em matéria de prestação de serviços à comunidade, às Faculdades de Direito incumbe a urgente tarefa de complementar o ensino teórico com o cuidado constante em aproximar os estudantes da massa imensa de pobres e miseráveis. Nossos alunos deveriam ser treinados para revelar, a todos eles, os direitos humanos que a Constituição lhes reconhece, e a habilitá-los a exigir o seu cumprimento.

Mas não é só essa a grande carência funcional das Universidades no momento presente.

Vivemos, neste início do vigésimo primeiro século da era cristã, uma etapa decisiva na História. Trata-se de saber se, ao cabo de um movimento multimilenar de reunião da espécie humana no espaço limitado e convergente do planeta, seremos enfim capazes de reunir os povos do mundo num convívio harmônico e solidário, fundado no respeito à dignidade eminente do ser humano; ou se iremos todos sucumbir, miseravelmente, à dominação destruidora da minoria rica, poderosa e irresponsável.

O principal objetivo da educação superior, no mundo atual, consiste, pois, em formar profissionais aptos a enfrentar esse magno desafio, e a escolher o bom lado: a construção daquela communis humani generis societas (a sociedade universal do gênero humano), de que falou Cícero há mais de vinte séculos; uma sociedade centrada em torno da Vida, no sentido bíblico da palavra, isto é, da plenitude do ser.

Ao iniciar sua marcha pelos caminhos da História, o povo brasileiro caiu nas mãos de assaltantes, que o maltrataram, deixando-o inconsciente à beira da estrada. Por ali passaram, no correr dos séculos, altas personalidades, inclusive Professores de Direito. Eles viram o estado lastimável da vítima, mas não se detiveram para socorrê-la.

Minha ardente esperança é não deixar esta vida, antes de ver a nossa juventude, em especial a valorosa mocidade das Arcadas, tal como o bom samaritano da parábola evangélica, vir em socorro do povo brasileiro. Que ela o ajude a pôr-se de pé, a fim de que possa, juntamente com os demais povos irmãos, construir um mundo novo, fundado na Verdade, na Justiça e no Amor.

Arcadas, 23 de setembro de 2009. 